\title{
Therapeutic potential of semi-mature dendritic cells for tolerance induction
}

\section{Manfred B. Lutz *}

Institute of Virology and Immunobiology, University of Wuerzburg, Wuerzburg, Germany

Edited by:

Stephen Paul Cobbold, University of Oxford, UK

\section{Reviewed by:}

Giovanna Lombardi, Kings College London, UK

Daniel Benitez-Ribas, CIBERehd,

Spain

\section{*Correspondence:}

Manfred B. Lutz, Institute of Virology and Immunobiology, University of

Wuerzburg, Versbacher St. 7, 97078

Wuerzburg, Germany.

e-mail:m.lutz@vim.uni-wuerzburg.de
Dendritic cells (DCs) are major players in the control of adaptive tolerance and immunity. Therefore, their specific generation and adoptive transfer into patients or their in vivo targeting is attractive for clinical applications. While injections of mature immunogenic DCs are tested in clinical trials, tolerogenic DCs still are awaiting this step. Besides the tolerogenic potential of immature DCs, also semi-mature DCs can show tolerogenic activity but both types also bear unfavorable features. Optimal tolerogenic DCs, their molecular tool bar, and their use for specific diseases still have to be defined. Here, the usefulness of in vitro generated and adoptively transferred semi-mature DCs for tolerance induction is outlined. The in vivo targeting of semi-mature DCs as represented by steady state migratory DCs are discussed for treatment of autoimmune diseases and allergies. First clinical trials with transcutaneous allergen application may point to their therapeutic use in the future.

Keywords: dendritic cells, tolerance, epicutaneous, transcutaneous, steady state, migration

\section{IMMATURE DCs}

Tolerogenicity of dendritic cells (DCs) has been shown by many experiments in vitro and in vivo (Manicassamy and Pulendran, 2011). There has been a debate whether certain subsets or the maturation/activation state defines DC tolerogenicity. In mice, all known lymphoid organ DC subsets have been demonstrated to bear tolerogenic potential, as shown for $\mathrm{CD}^{+}$(Sato et al., 2003b; Chung et al., 2005), CD8 $\alpha^{+}$(Belz et al., 2002; Ferguson et al., 2002; Yamazaki et al., 2008), and plasmacytoid DC (pDC) subsets (Martin et al., 2002; Ochando et al., 2006; Hadeiba et al., 2008) but also human monocyte-derived DCs (Sato et al., 2003a). Conditional ablation of DCs during the steady state in mice results in a loss of self-tolerance (Birnberg et al., 2008; Ohnmacht et al., 2009). Experimental animal models in transplantation, autoimmunity or allergy and indications from human studies suggest a tolerogenic potential of immature DCs (Bluestone et al., 2007; Morelli and Thomson, 2007; Hilkens et al., 2010; Manicassamy and Pulendran, 2011). Human immature DCs, loaded with the influenza matrix peptide and keyhole limpet hemocyanin and then injected i.v. into healthy individuals induced tolerance (Dhodapkar et al., 2001). Together, not a defined DC subset or the presentation of foreign antigens dictates DC tolerogenicity but their maturation state.

In vivo most of tissue- and lymphoid organ-resident DCs are immature (Wilson et al., 2003) but after ex vivo isolation they lose their tolerogenic potential due to maturation induced by the preparation procedure (Maldonado-López et al., 1999). Thus, immature DCs need to acquire maturation resistance to subsequent stimuli to act strictly tolerogenic. This can be achieved for in vitro generated DCs by specific conditioning to preserve

Abbreviations: APC, antigen-presenting cells; DCS, dendritic cells; Th1, T helper 1; Th2, T helper 2; Th17, $\mathrm{T}$ helper 17; Tregs, regulatory $\mathrm{T}$ cells; $\operatorname{Tr} 1, \mathrm{~T}$ regulatory type $1 ;$ TNF/DCS, TNF-matured DCS. their immature state (Thomson, 2010). Alternatively, targeting of immature DCs in vivo can be used to induce tolerance by targeting certain surface receptors that mediate tolerance, such as first demonstrated for the 33D1 (DCIR2) antibody binding to the $\mathrm{CD}^{+}$DC subset (Finkelman et al., 1996) and later for the CD8 $\alpha^{+}$DC subset by DEC205 (CD205) antibody (Hawiger et al., 2001).

As a third possibility intravenous injection of soluble antigens reach thymic and splenic DCs, which are then presented under steady state conditions with half-lives between 3 and $22 \mathrm{~h}$ (Muller et al., 1993). Soluble protein injections such as myelin antigens may reach preferentially the $\mathrm{CD} 4^{+} \mathrm{CD} 11 \mathrm{~b}^{+} \mathrm{DCs}$ and can lead to protection from autoimmunity (Li et al., 2008). Injected apoptotic cells as a source for tolerogenic antigens are captured by spleen DCs and may represent promising tolerogenic tools in allogeneic transplantation settings (Steinman et al., 2000; Morelli and Larregina, 2010).

It is of note that s.c. injection of immature DCs leads to their upregulation of costimulatory molecules and a loss of tolerogenicity (Fu et al., 1996). TNF-matured DCs that were tolerogenic when injected i.v., turn into highly immunogenic DCs when applied the s.c. route (Voigtländer et al., 2006). This may indicate that tissue injury mediated maturation by ex vivo isolation procedures or via the s.c. injection route causes danger signals strong enough to abrogate tolerogenicity of immature DCs. Recently, human autologous monocyte-derived DCs, treated with antisense oligonucleotides against CD40, CD80, and CD86 but not loaded with specific antigens were injected intradermally into type 1 diabetes patients (Giannoukakis et al., 2011). Although these DCs were not further characterized, not even on the stability of the costimulation blockade, they appeared save for the patients but also without clinical benefit. Thus, DC injections or in vivo targeting may prefer the i.v. route or require specific treatments to gain maturation resistance. 


\section{MATURE DCs}

Mature DCs or, as we proposed earlier, rather fully mature DCs (Lutz and Schuler, 2002), are inducers of effector T cell responses by their costimulation, homing, and cytokine production capacities and therefore candidates for anti-microbial or tumor vaccine approaches (Steinman, 2008). Further "licensing" of DCs through CD40 signals leads to elevated cytokine secretion and resistance to Treg-mediated loss of costimulatory molecules on mature DCs (Hänig and Lutz, 2008; and references therein). However, although immature DCs are more efficient in Treg de novo induction from naive T cells, mature DCs have been demonstrated to act superior in activating the suppressor function of Tregs. Details on the role of DC costimulation for Treg generation and function has been reviewed elsewhere (Pletinckx et al., 2011a).

\section{SEMI-MATURE DCs}

Partial maturation resulting in upregulation of MHC and costimulatory molecules and lymph node homing capacity but lack of proinflammatory cytokine production was termed semimaturation (Lutz and Schuler, 2002). An advantage of semimature tolerogenic DCs over immature tolerogenic DCs is their lymph node homing potential by which DCs can reach $\mathrm{T}$ cells at their anatomical locations. Although under debate, to create the term "semi-maturation" allowed the collection of arguments for or against it and then to keep or discard it. So far, further experimental evidences for the phenotype and tolerogenic potential of semi-mature DC stages have been obtained and reviewed (Mills and McGuirk, 2004; Morelli et al., 2005; Braun et al., 2006; Nouri-Shirazi and Thomson, 2006; Rutella et al., 2006; van Duivenvoorde et al., 2006; Young et al., 2007; Frick et al., 2010; Morel and Turner, 2011). Recently, gene-expression profiling of different semi-mature DCs (TNF, Trypanosoma antigens) was compared to fully mature DCs (LPS) and revealed mainly quantitative differences between these DC types. A common signature of only 24 proinflammatory genes characterized the semi-mature DC types with a total of 160-466 genes regulated as opposed to almost 5000 genes regulated by LPS (Pletinckx et al., 2011b). These data underline that besides the qualitative instruction of pathogen- versus self-antigen-recognition by triggering or not of pattern recognition receptors also more fine-tuned quantitative differences in gene regulation seem to determine DC tolerogenicity versus immunogenicity (Figure 1). Here, some specific aspects of semi-mature tolerogenicity will be discussed.

\section{TOLEROGENICITY OF SEMI-MATURE DCs}

Initial findings in the mouse, that TNF-matured bone-marrowderived DCs (TNF/DCs) and intravenously injected into mice could act tolerogenic (Menges et al., 2002) were similar to findings that cross-tolerance of $\mathrm{CD}^{+} \mathrm{T}$ cells in vitro induced by human DCs also required TNF stimulation (Albert et al., 2001). Repetitive injections of peptide-loaded TNF/DCs into mice allowed complete protection from experimental autoimmune encephalomyelitis (EAE). The resulting $\mathrm{T}$ cell response was characterized by a lowered IFN- $\gamma$ production, absence of IL- 4 , and increased IL-10 production of CD4 ${ }^{+} \mathrm{T}$ cells as detected by ELISA (Menges et al., 2002). Thus, a tolerogenic response being compatible with induction of a regulatory $\mathrm{T}$ cell type 1 ( $\operatorname{Tr} 1)$ (Roncarolo et al., 2006). Similar observations have been made with TNF/DCs in a murine thyroiditis model (Verginis et al., 2005), DNA-matured DCs in experimental collagen-induced arthritis (Jaen et al., 2009), MyD88-silenced, and then LPS-matured DCs in rat intestinal allograft transplantation (Yang et al., 2011). Others generated semi-mature DCs by dexamethasone and 1 $\alpha, 25$-dihydroxyvitamin D3 (VD3) treatment alone (Unger et al., 2009) or in parallel with LPS exposure

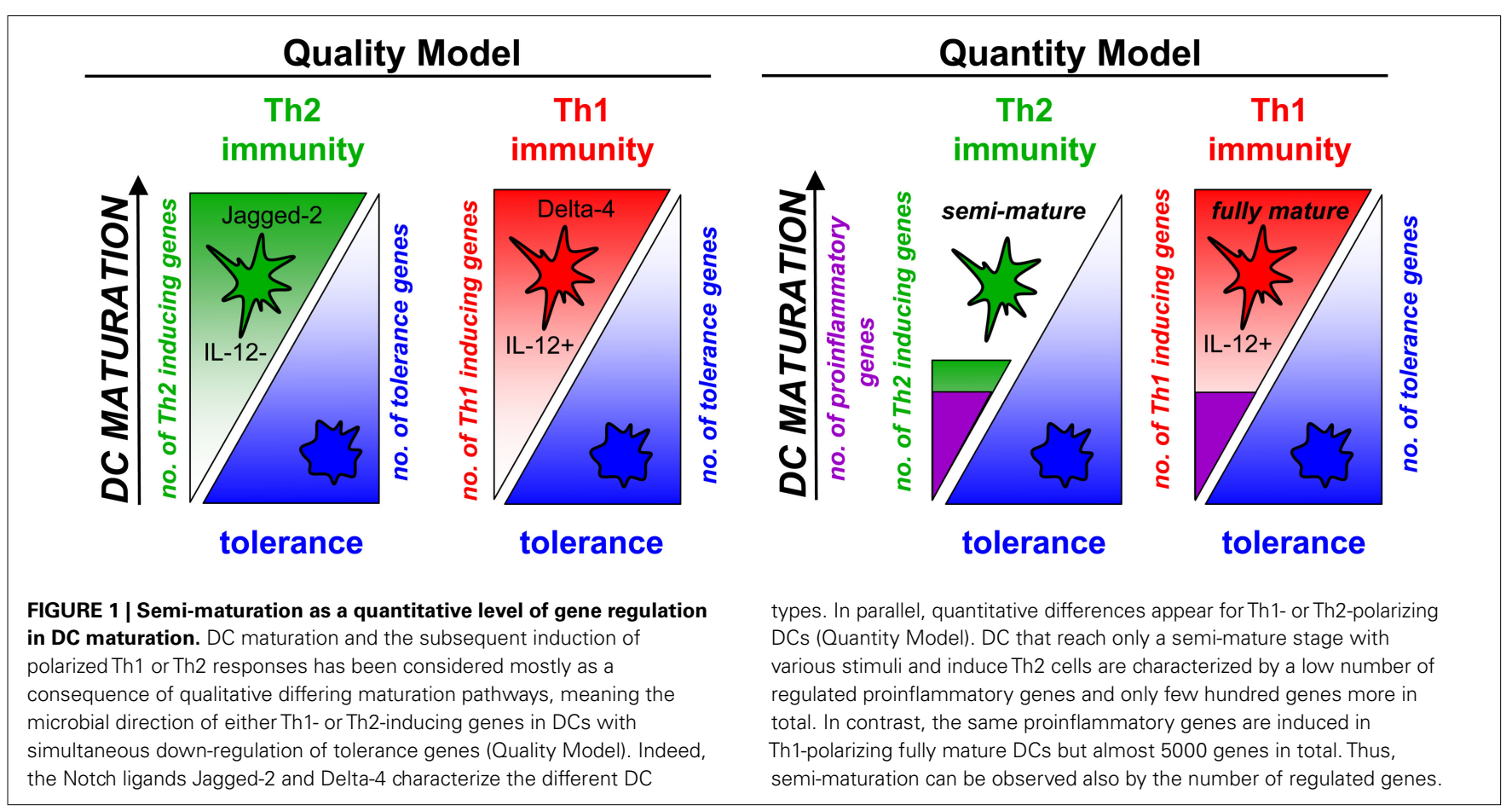


of cells that were protective in collagen-induced arthritis model (Stoop et al., 2010). Semi-mature DCs generated by sequential dexamethasone and LPS treatment were superior to immature DCs to prolong allograft survival in mice (Emmer et al., 2006). In a murine graft versus of note, in macaques a tolerogenic DC semi-maturation stage seems to be achieved by using bone marrow as a source but not peripheral blood monocytes (Moreau et al., 2008). When human monocyte-derived DCs were generated in GM-CSF, IL-4, TGF- $\beta$, and IL- 10 for 7 days the resulting regulatory immature DCs could respond to TNF only by partial upregulation of costimulatory molecules as compared to DCs cultured without TGF- $\beta$ and IL-10 (Sato et al., 2003a). Unfortunately, their cytokine production, CCR7 expression or homing potential was not tested and the murine counterparts generated from bone marrow appeared rather immature, although successful in the treatment of graft-versus-host disease model (Sato et al., 2003a,b).

A recent study tested the clinical potential of different human monocyte-derived semi-mature DCs, considering also CCR7dependent homing potential and maturation stability (Boks et al., 2012). Human immature monocyte-derived DCs were compared with DCs that received additional treatments of dexamethasone, rapamycin, TGF- $\beta$, or IL- 10 . The results indicated that the treatments with the inhibitors for $1 \mathrm{~h}$, revealed immature DCs without migration capacity, while following cocktail maturation (TNF, IL-1 $\beta, \mathrm{PGE}_{2}$ ) allowed the acquisition of migratory capacity on CCL21 in vitro and maturation resistance to further TLR exposure. However, it appeared that IL-10, the strongest inhibitor of DC maturation and the best Treg inducer, also showed the poorest migration, indicating that a balanced inhibition/maturation protocol will be essential for successful application of semimature DC in the clinic. Together, weak maturation stimuli alone or combinations of suppressive treatments followed by maturation stimuli leads to partial DC maturation with tolerogenic capacity.

\section{ROLE OF REPETITIVE SEMI-MATURE DC INJECTIONS}

After establishing that repetitive injections of TNF/DCs lead to $\operatorname{Tr} 1$ cell generation (Menges et al., 2002) additional studies in our lab indicated that this might be a result of chronic Th2 immunity. After peptide restimulation of spleen cells from IL-4R deficient mice in the EAE protection model IL-4 production by ELISA (and in addition IL-13) was detectable (Wiethe et al., 2008), indicating that low amounts of IL-4 were produced in wild-type mice but consumed completely and therefore not detectable. Intracellular flow cytometry showed that both $\mathrm{CD} 4{ }^{+}$T cells and NKT cells recognize peptide or glycolipid antigens presented by TNF/DCs leading to their IL-4 and IL-13 production. More detailed investigations on CD1d presentation by TNF/DCs identified both type I and II NKT cells to secrete these cytokines (Wiethe et al., 2007). A further augmented activation of so-called non-classical or type II NKT cells, i.e., CD1d-restricted and glycolipid-recognizing CD4 ${ }^{+} \mathrm{T}$ cells with a diverse TCR repertoire (Godfrey et al., 2004), was observed when the co-inhibitory molecule B7-H1/PD-L1 was absent on the DCs (Brandl et al., 2010). Thus, repetitive TNF/DC injections induce IL-10, little IL-4, and IL-13 production of conventional CD4 ${ }^{+}$ $\mathrm{T}$ cells (Figure 2 ), together with IL-4, IL-13, but not IL-10, by invariant type I NKT cells as well as by non-classical type II NKT cells.

Recent analyses showed that a single stimulation of $\mathrm{T}$ cells by TNF/DCs induced a Th2-like profile in vitro and in vivo (Pletinckx et al., 2011b), that allows immune deviation of antigenspecific $\mathrm{T}$ cells away from pathogenic Th1 and Th17 responses in EAE. Only repetition leads to dominant $\operatorname{Tr} 1$-mediated control of EAE. We also tested whether this mixed $\mathrm{Th} 2 / \operatorname{Tr} 1$ response would influence asthma as a Th2 disease model. The data revealed that TNF/DCs could neither boost nor protect Th2-mediated asthma in mice, presumably pointing to a neutral effect of Th2booster together with Tr1-suppression (Pletinckx et al., 2011b). This is different to what has been described by others with intranasally applied OVA allergen also leading to $\operatorname{Tr} 1$ cells without additional Th2 induction and protecting from asthma (Akbari et al., 2001). These differences in the clinical outcome may however, also be explained by IL-10 production by the endogenous lung DCs after intranasal asthma therapy, which was not observed with our adoptively transferred TNF/DCs. Alternatively, a local control of the disease in lung lymph nodes (Akbari et al., 2001) rather than systemically injected TNF/DCs, reaching the spleen, may be beneficial in the asthma model. Together, semi-mature DC-induced mixed $\mathrm{Th} 2 / \mathrm{Tr} 1$ responses can protect from Th1/Th17-induced (Sato et al., 2003a) diseases but pure $\operatorname{Tr} 1$ induction will be necessary to treat also Th2-mediated diseases.

\section{INFLAMMATION, PATHOGENS, COMMENSALS, AND TUMORS AS INDUCERS OF SEMI-MATURATION}

There is accumulating evidence that typical Th2-inducing pathogens also induce only partial DC maturation such as shown for Leishmania amazonensis (Prina et al., 2004), Bordetella pertussis (Vojtova et al., 2006), cholera toxin (Bimczok et al., 2007), Nippostrongylus brasiliensis (Balic et al., 2004), or Echinococcus multilocularis (Nono et al., 2012). As a consequence the resulting Th2 response will be dominated by $\operatorname{Tr} 1$ cells due to the chronicity of the infection (O'Garra et al., 2004) and was similar as observed for repetitive injections of TNF/DCs in the autoimmune models mentioned above. In addition, commensals such as Lactobacillus rhammnosus (Veckman et al., 2004) or Bacteroides vulgatus (Frick et al., 2006) but also exogenous noxes such as nicotine (Hu et al., 2012) or endogenous inflammasome triggers such as ATP (Ben Addi et al., 2008) can induce partial DC maturation.

Receptors that mediate semi-maturation include both TNFR1 and TNFR2 (Funk et al., 2000), IL-6R (Frick et al., 2010), allergen targeting to Fc $\gamma \mathrm{R}$ I (Hulse and Woodfolk, 2008) but also Trypanosoma brucei-derived VSG antigens with presumably low affinities for MyD88-dependent Toll-like receptors (TLR; Pletinckx et al., 2011b). Treatment of human patients with psoriasis and multiple sclerosis by fumaric acid similarly induces a Th2inducing DC type (Ghoreschi et al., 2011). In sum, inflammatory mediators, commensal bacteria, or typical Th2-pathogens can induce DC semi-maturation. This may indicate that commensals and pathogens exploit "this is only an inflammation" signaling pathways in DCs to escape strong immunity and elimination but also immunopathology (MacDonald and Maizels, 2008). 


\section{immature tissue-resident DC}

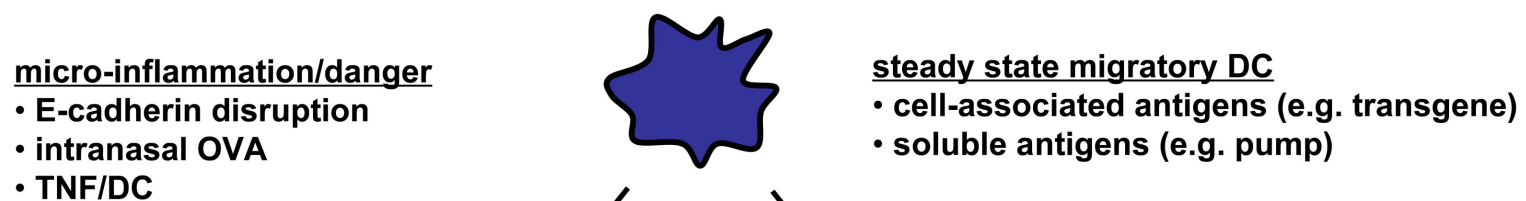

- TNF/DC

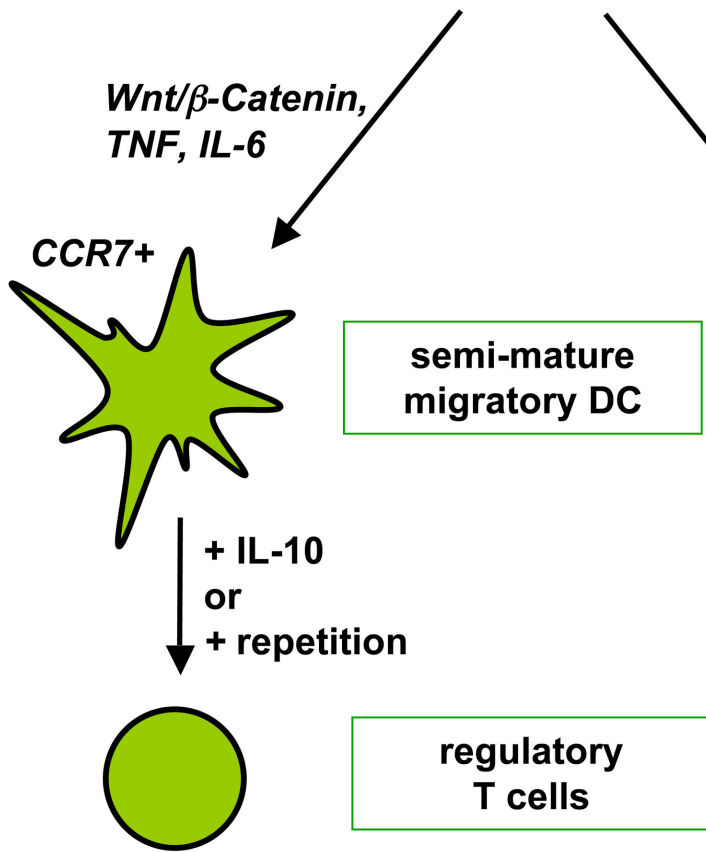

IL-10+ Tr1
Foxp3 $^{+} \mathrm{T}_{\text {reg }}$
FIGURE 2 |Two distinct DC semi-maturation pathways induce different types of regulatory T cells. Immature tissue-resident DCs or in vitro generated BM-DCs that are triggered through the $\mathrm{Wnt} / \beta$-catenin pathway or proinflammatory cytokines become semi-mature DC with migratory potential to T cell areas. Upon induction of IL-10 production by the DCs as observed via intranasal antigen application $\operatorname{Tr} 1$ cell generation from naive $T$ cells is favored.
Alternatively, repetitive injections of IL-10-deficient semi-mature DC also lead to Tr1 cell generation. Different, only incompletely understood maturation pathways activate tissue-resident $\mathrm{DC}$ into RelB/p52+ semi-mature DCs homing to the T cell areas of peripheral lymph nodes. Transport of soluble and cell-associated antigens have been observed for ssmDCs. By using TGF- $\beta$ and retinoic acid naive T cells are converted into Foxp3+ ${ }^{+}$Tregs by ssmDCs.
It has been shown that a mild DC activation can occur through disrupting DC-DC contacts formed by homotypic interaction via E-cadherin and this dissociation is indeed accompanied by partial maturation of the DCs through the Wnt/ $\beta$-catenin signaling pathway (Jiang et al., 2007). These disrupted DCs upregulated MHC II and costimulatory molecules but did not secrete proinflammatory cytokines. When pulsed with myelin antigen they induced IL-10 producing T cells that controlled EAE (Jiang et al., 2007) using the same protocol and reaching very similar results as demonstrated by our group with TNF/DCs before (Menges et al., 2002). In a colitis model Wnt signals activating $\beta$-catenin in DCs were required to control the disease, indicative for a tolerogenic DC activation (Manicassamy et al., 2010). However, so far it remains unclear whether DCs matured along the $\beta$-catenin pathway are resistant to further stimulation that would be demanding for therapeutic use.

Finally, in human patients suffering from pancreatic ductal adenocarcinoma or chronic pancreatitis conventional DCs and pDCs isolated from the peripheral blood appeared at a semi-mature stage with impaired stimulatory function on T cells (Tjomsland et al., 2010). Similarly, DC infiltrating tumors of non-small cell lung cancer patients appeared immature or semi-mature or remained semi-mature when exposed to maturation stimuli (Perrot et al., 2007). Further investigations have to elucidate whether such DCs are actively tolerogenic.

\section{LIMITATIONS OF SEMI-MATURE DC TOLEROGENICITY}

As already mentioned above injections of semi-mature DCs protected from Th1/Th17 immunity in the EAE model but not in Th2-mediated asthma (Pletinckx et al., 2011b). In addition, TNF/DC application for EAE therapy, i.e., after EAE induction, failed (our unpublished observations). The reasons for this failure, however, are obvious. In the preventive setting a large part of the auto-antigen-specific naive $\mathrm{CD} 4^{+} \mathrm{T}$ cell repertoire is primed and polarized into Th2 and subsequently into $\operatorname{Tr} 1$ phenotypes. If EAE induction follows by immunization with the same auto-antigenic peptide, the frequency of the remaining auto-antigen-specific 
naive $\mathrm{CD} 4^{+} \mathrm{T}$ cells is insufficient to generate enough pathogenic Th1 and Th17 cells. This is the principle of tolerance induction by immune deviation. Reversely, if most auto-antigen-specific cells are polarized into Th1 or Th17 cells by the EAE protocol, it is difficult at later time points to generate enough protective Th2 or Tr1 cells from the remaining antigen-specific $\mathrm{T}$ cell pool. Thus, tolerance induction by immune deviation or induced Tregs/Tr1 cells relies on sufficient numbers of naive auto-antigen-specific $\mathrm{T}$ cells at the time of therapy.

In a type I diabetes model TNF/DCs loaded with an autoantigenic peptide on $\mathrm{MHC}$ class I molecules also failed to act tolerogenic on $\mathrm{CD}^{+} \mathrm{T}$ cell autoimmunity (Kleindienst et al., 2005), indicating that the DC semi-maturation may not allow tolerization of high affinity $\mathrm{CD}^{+} \mathrm{T}$ cells such as the OT-I transgenic $\mathrm{T}$ cells used in this system. Furthermore, dose-dependent effects have been observed in collagen-induced arthritis, where semi-mature DCs injected at low amounts were protective whereas high amounts failed to do so (Lim et al., 2009).

As for immature DCs also the stability of the semi-mature phenotype is important to maintain tolerogenicity and for this the injection route may play an essential role. While three i.v. injections of TNF/DCs were completely protective in the EAE model, s.c. application of the same DCs was deleterious and all mice died from severe EAE. One reason was a remaining responsiveness of TNF/DCs to further maturation signals such as LPS in vitro, which led to IL-12 production. In vivo, TNF/DCs injected s.c. homed to the draining lymph node but appeared cytokine negative unlike endogenous DCs, which showed proinflammatory cytokine production (Voigtländer et al., 2006). This indicates that s.c. injection abrogates semi-mature DC tolerogenicity, in part by interactions with other DCs. In cancer patients, only s.c. or intralymphatic but not i.v. injections of DCs matured with tumor antigens could prime Th1 responses, while $\mathrm{T}$ cell activation was observed under all conditions (Fong et al., 2001), but tolerogenic parameters were not analyzed for the i.v. settings. Interestingly, intracerebral injections of TNF/DCs in mice still could act tolerogenic (Zozulya et al., 2009).

As mentioned above, it will be necessary to establish semimature DCs that remain stable, and this might be achieved by subsequent treatment with a maturation inhibitor followed by a maturation inducer (Sato et al., 2003a; Boks et al., 2012).

\section{STEADY STATE MIGRATORY DCS IN VIVO COUNTERPARTS OF IN VITRO GENERATED SEMI-MATURE DCs?}

After all, the question remained whether semi-mature stages of DCs can be detected in vivo and whether they also exert tolerogenic functions. Early observations indicated that the afferent lymph contained "veiled cells" representing DCs with dendrites as a sign of their maturity (reviewed in (Lutz and Schuler, 2002). Later it has been shown that peripheral lymph nodes of mice contained a fraction of DCs that expressed high levels of MHC II and the costimulatory molecules CD80, CD86, and CD40 on their surface (Ruedl et al., 2000; Henri et al., 2001). Another remarkable similarity of these lymph node DCs was their endocytosis capacity despite the mature cell surface marker profile (Ruedl et al., 2001), indicative for an incomplete maturation. These partially mature DCs exclusively represent the immigrated steady state migratory fraction of formerly skin-resident DCs. Their migration through the lymphatics depends on CCR7 expression like for pathogen-induced migratory DCs (Ohl et al., 2004). They consist of three major subsets, identified as epidermal Langerhans cells (LCs), dermal Langerin ${ }^{+}$, and dermal Langerin ${ }^{-}$DC subtypes (Romani et al., 2010), although even more subsets or functional states may exist (Henri et al., 2010). Also the intestine contains CCR7-dependent state migratory DCs (ssmDCs) but they appear less mature after arrival in mesenteric lymph nodes as compared with their skin migratory counterparts (Worbs et al., 2006). The reasons for this are unclear.

Analyses in pigs revealed that their skin-draining lymph nodes contained ssmDC and they appear at a semi-mature state (Bertho et al., 2011). Human tonsils contain a mature DC fraction (Summers et al., 2001) but it remains to be shown that these cells are not resident DCs matured by inflammatory processes since tonsils lack connection to afferent lymphatics and surgical removal of tonsils (which enable such studies) are indicated only after chronic inflammations. Analyses of human peripheral lymph nodes from tumor-free melanoma patients, and thereby considered as steady state lymph nodes, contained two subsets of skin-derived CD1a ${ }^{+}$ CD $11 c^{\text {int }}$ LCs and CD1a ${ }^{+}$CD11 $c^{\text {high }}$ dermal DCs (van de Ven et al., 2011). Both subsets expressed more CD80, CD86 CD40, and CD83 as compared to their resident counterparts. Despite their more mature phenotype, these DCs produced lower amounts of proinflammatory cytokines and were weaker in priming $\mathrm{T}$ cell responses, indicative for primarily tolerogenic functions. Supernatants of human tumor cell lines (Kuang et al., 2008) could induce partial DC maturation in vivo, similar to what has been observed in pancreatic adenocarcinomas (Tjomsland et al., 2010) and non-small cell lung cancers (Perrot et al., 2007) where such cells accumulated in the tumor tissue.

Together, ssmDCs of the skin-draining lymph nodes in mice, pigs, and humans DCs display a semi-mature phenotype by expressing higher costimulatory molecules and having the homing capacity to lymph nodes.

\section{TOLEROGENIC FUNCTIONS OF ssmDCs}

It became evident from early studies that ssmDCs transport selfantigens to the draining lymph nodes (Huang et al., 2000; Hemmi et al., 2001), but the consequences for T cells by the presentation of these antigens were still open, although tolerance induction was proposed. Subcutaneously implanted osmotic minipumps indicated that Foxp $3^{+}$Tregs could be de novo converted by this type of constant low dose soluble antigen delivery (Apostolou and von Boehmer, 2004). Later we could show that this low dose soluble antigen delivery by the pump system requires $\mathrm{RelB}^{+} / \mathrm{p} 52^{+}$ CCR7 $^{+}$ssmDCs (Azukizawa et al., 2011). Since pump implantation requires a surgical intervention, this system may not fully represent steady state conditions, despite equivalent induction of Tregs. Direct comparison of soluble antigen delivery via subcutaneous minipumps with cell-associated transgenic neo-self-antigen expression of OVA in the epidermis (K5-mOVA mice), revealed the same dependency on ssmDCs with the same kinetics and frequency of CD4 ${ }^{+}$Treg induction (Azukizawa et al., 2011; Figure 2) or $\mathrm{CD}^{+} \mathrm{T}$ cell depletion (Waithman et al., 2007). Recent data suggest that ssmDCs may control the whole pool of homeostatic 
lymph node $\mathrm{T}$ cell circulation by producing VEGF that stimulated formation of high endothelial venules (HEVs) to enable $\mathrm{T}$ cell entry and stimulated fibroblastic reticular cells to secrete CCL21 that acts chemotactic for T cells (Wendland et al., 2011). Thus, ssmDCs control $\mathrm{T}$ cell homeostasis in peripheral lymph nodes and act tolerogenic on $\mathrm{CD}^{+}{ }^{+}$and $\mathrm{CD} 8^{+}$T cells, unlike TNF/DCs.

It is however unclear to date what distinguishes these ssmDCs in the mentioned self-antigen model systems that induced IL-10 ${ }^{-}$ Foxp $3^{+}$Tregs from ssmDCs that captured exogenous OVA or Bordetella flagellin that was applied intranasally and induced IL-10 ${ }^{+}$ Foxp3 ${ }^{-}$Tr1 cells (Akbari et al., 2001; McGuirk et al., 2002). One possibility could be that tolerogenic immune evasion strategies of bacterial flagellin or low doses of endotoxin attached to OVA may lead to IL-10 release by the DCs, which is not observed under completely pathogen-free conditions.

\section{IN VIVO TARGETING OF sSmDCs FOR TOLERANCE INDUCTION}

The existence of ssmDCs, which bear lymph node homing potential, are partially mature but still tolerogenic, offer their clinical exploitation by specific targeting. In fact earlier studies may have targeted ssmDCs for tolerance induction in an unscheduled manner. We found that DEC205 is expressed at higher levels on ssmDCs than lymph node resident or splenic DCs (own unpublished observations). Therefore antigen-targeting to this marker by i.v. injection may also or even preferentially target ssmDC in peripheral lymph nodes (Hawiger et al., 2001; Kretschmer et al., 2005).

An alternative route to reach ssmDCs is via epicutaneous antigen application. Plaster-mediated delivery of self-antigenic myelin peptide was able to prevent EAE induction (Bynoe et al., 2003; Szczepanik et al., 2005). Although not further investigated, it is likely that ssmDCs have been the vehicle to induce myelinspecific Tregs in the skin-draining lymph nodes. Surprisingly, even approaches using gene gun delivery of antigens, that has been developed for immunogenic vaccines, may be used to induce stable tolerance by induction of Foxp3 + Tregs and this may occur through ssmDCs (Ettinger et al., 2012).

This principle of targeting ssmDCs through the skin may also account for tolerogenic strategies in allergy treatment (Werfel, 2009; Senti et al., 2011). Such treatment showed therapeutic success in murine allergy models using OVA, pollen, house dust mite, or peanut as allergens (Mondoulet et al., 2010, 2011, 2012; Dioszeghy et al., 2011). First clinical studies using epicutaneous immunotherapy in childhood cow milk allergy patients demonstrated safety although the three months of treatment did not reach therapeutic success (Dupont et al., 2010). The reversal of an existing allergy may need extended periods of treatment as suggested from other studies in patients with pollen allergy that showed a moderate benefit (Senti et al., 2009, 2010). Alternatively, the intranasal application route may be superior to the skin and also employs partially mature migratory DCs and led to $\operatorname{Tr} 1$ induction in the pulmonary lymph nodes (Akbari et al., 2001).

\section{REFERENCES}

Akbari, O., Dekruyff, R. H., and Umetsu, D. T. (2001). Pulmonary dendritic cells producing IL-10 mediate tolerance induced by respiratory exposure to antigen. Nat. Immunol. 2, 725-731.

Albert, M. L., Jegathesan, M., and Darnell, R. B. (2001). Dendritic cell maturation is required

Finally, the potential success of such epicutaneous or transcutaneous tolerance strategies may be encouraged by the fact that some pathogens hitchhike ssmDCs for immune evasion. A prominent example is HIV, which infects peripheral immature DCs resident in the skin or mucosa and then awaits to be transported to the draining lymph nodes for further infection of $\mathrm{CD} 4{ }^{+} \mathrm{T}$ cells as their major targets, and even converting some of these into HIV-specific Tregs (Smed-Sorensen and Lore, 2011). Together, semi-mature DCs as represented by ssmDCs may prove valuable targets for clinical epicutaneous or transcutaneous tolerance induction protocols in the future.

\section{SEMI-MATURE pDCs}

So far this review concentrated on conventional/myeloid semimature DC or ssmDCs. However, this does not exclude the existence of semi-mature stages also for pDCs. The biology of pDCs is very different as compared to conventional DCs but certainly they have in common to present antigens to $\mathrm{T}$ cells in tolerogenic or immunogenic fashions.

Recent data indicate that pDCs infected in vitro with HIV may be modified by the virus to reach a semi-mature stage that facilitates Treg induction (Smed-Sorensen and Lore, 2011). Similar observations have been made with tumor-infiltrating pDCs that show impaired maturation potential but without providing $\mathrm{T}$ cell assays (Perrot et al., 2007; Tjomsland et al., 2010). In contrast, freshly isolated pDC from mice also appeared semi-mature, but pulsed with Leishmania antigen and reinjected into mice showed a protective effect, indicative for their immunogenic activity (Remer et al., 2007).

Together, more detailed analyses for pDCs are required to evaluate a therapeutic potential of semi-mature pDCs.

\section{CONCLUSION}

The initially surprising finding that partially matured DCs can still act tolerogenic has now reached a broader base by numerous reports and more mechanistic insights. Semi-mature DCs can be generated in vitro and exert a distinct spectrum of tolerogenicity after injection. The finding that semi-mature ssmDCs are continuously engaged to tolerize lymph node $\mathrm{T}$ cells against peripheral self-antigens opens further perspectives for therapies, especially against autoimmune diseases and allergies. Thus, tolerogenic regimens employing semi-mature DCs may in the future either be concentrated on in vivo targeting with antibodies or transcutaneous antigen application regimens.

\section{ACKNOWLEDGMENTS}

The author is grateful for support by the German Research Foundation (DFG) through grants within the TR52, SFB581, IRTG1522, IZKF Würzburg and by an individual DFG grant LU851/6-1. This publication was funded by the German Research Foundation (DFG) and the University of Wuerzburg in the funding program Open Access Publishing.

for the cross-tolerization of CD8+ T cells. Nat. Immunol. 2, 1010-1017.

Apostolou, I., and von Boehmer, $\mathrm{H}$. (2004). In vivo instruction of suppressor commitment in naive $\mathrm{T}$ cells. J. Exp. Med. 199, 1401-1408.

Azukizawa, H., Dohler, A., Kanazawa, N., Nayak, A., Lipp, M., Malissen, B., Autenrieth, I., Katayama, I., 
Riemann, M., Weih, F., BerberichSiebelt, F., and Lutz, M. B. (2011). Steady state migratory RelB+ langerin+ dermal dendritic cells mediate peripheral induction of antigenspecific CD4+ CD25+ Foxp3+ regulatory T cells. Eur. J. Immunol. 41, 1420-1434.

Balic, A., Harcus, Y., Holland, M. J., and Maizels, R. M. (2004). Selective maturation of dendritic cells by Nippostrongylus brasiliensis-secreted proteins drives Th2 immune responses. Eur. J. Immunol. 34, 3047-3059.

Belz, G. T., Behrens, G. M., Smith, C. M., Miller, J. F., Jones, C., Lejon, K., Fathman, C. G., Mueller, S. N., Shortman, K., Carbone, F. R., and Heath, W. R. (2002). The CD8alpha(+) dendritic cell is responsible for inducing peripheral self-tolerance to tissueassociated antigens. J. Exp. Med. 196, 1099-1104.

Ben Addi, A., Lefort, A., Hua, X., Libert, F., Communi, D., Ledent, C., Macours, P., Tilley, S. L., Boeynaems, J. M., and Robaye, B. (2008). Modulation of murine dendritic cell function by adenine nucleotides and adenosine: involvement of the A(2B) receptor. Eur. J. Immunol. 38, 1610-1620.

Bertho, N., Marquet, F., Pascale, F., Kang, C., Bonneau, M., and Schwartz-Cornil, I. (2011). Steady state pig dendritic cells migrating in skin draining pseudoafferent lymph are semi-mature. Vet. Immunol. Immunopathol. 144, 430-436.

Bimczok, D., Rau, H., Wundrack, N., Naumann, M., Rothkotter, H. J., Mccullough, K., and Summerfield, A. (2007). Cholera toxin promotes the generation of semimature porcine monocyte-derived dendritic cells that are unable to stimulate $\mathrm{T}$ cells. Vet. Res. 38, 597-612.

Birnberg, T., Baron, L., Sapoznikov, A., Caton, M. L., Cervantes-Barragan, L., Makia, D., Krauthgamer, R., Brenner, O., Ludewig, B., Brockschnieder, D., Riethmacher, D., Reizis, B., and Jung, S. (2008). Lack of conventional dendritic cells is compatible with normal development and $\mathrm{T}$ cell homeostasis, but causes myeloid proliferative syndrome. Immunity 29, 986-997.

Bluestone, J. A., Thomson, A. W., Shevach, E. M., and Weiner, H. L. (2007). What does the future hold for cellbased tolerogenic therapy? Nat. Rev. Immunol. 7, 650-654.

Boks, M. A., Kager-Groenland, J. R., Haasjes, M. S., Zwaginga, J. J.,
Van Ham, S. M., and Ten Brinke, A. (2012). IL-10-generated tolerogenic dendritic cells are optimal for functional regulatory $\mathrm{T}$ cell induction - a comparative study of human clinical-applicable DC. Clin. Immunol. 142, 332-342.

Brandl, C., Ortler, S., Herrmann, T., Cardell, S., Lutz, M. B., and Wiendl, H. (2010). B7-H1deficiency enhances the potential of tolerogenic dendritic cells by activating CD1d-restricted type II NKT cells. PLOS ONE 5, e10800. doi:10.1371/journal.pone.0010800

Braun, D., Galibert, L., Nakajima, T., Saito, H., Quang, V. V., Rubio, M., and Sarfati, M. (2006). Semimature stage: a checkpoint in a dendritic cell maturation program that allows for functional reversion after signal-regulatory protein-alpha ligation and maturation signals. $J$. Immunol. 177, 8550-8559.

Bynoe, M. S., Evans, J. T., Viret, C., and Janeway, C. A. Jr. (2003). Epicutaneous immunization with autoantigenic peptides induces $\mathrm{T}$ suppressor cells that prevent experimental allergic encephalomyelitis. Immunity 19, 317-328.

Chung, Y., Chang, J. H., Kweon, M. N., Rennert, P. D., and Kang, C. Y. (2005). CD8alpha-11b+ dendritic cells but not CD8alpha+ dendritic cells mediate cross-tolerance toward intestinal antigens. Blood 106, 201-206.

Dhodapkar, M. V., Steinman, R. M., Krasovsky, J., Munz, C., and Bhardwaj, N. (2001). Antigen-specific inhibition of effector $\mathrm{T}$ cell function in humans after injection of immature dendritic cells. J. Exp. Med. 193, 233-238.

Dioszeghy, V., Mondoulet, L., Dhelft, V., Ligouis, M., Puteaux, E., Benhamou, P. H., and Dupont, C. (2011). Epicutaneous immunotherapy results in rapid allergen uptake by dendritic cells through intact skin and downregulates the allergenspecific response in sensitized mice. J. Immunol. 186, 5629-5637.

Dupont, C., Kalach, N., Soulaines, P., Legoue-Morillon, S., Piloquet, H., and Benhamou, P. H. (2010). Cow's milk epicutaneous immunotherapy in children: a pilot trial of safety, acceptability, and impact on allergic reactivity. J. Allergy Clin. Immunol. 125, 1165-1167.

Emmer, P. M., Van Der Vlag, J., Adema, G. J., and Hilbrands, L. B. (2006). Dendritic cells activated by lipopolysaccharide after dexamethasone treatment induce donor-specific allograft hyporesponsiveness. Transplantation 81, 1451-1459.

Ettinger, M., Peckl-Schmid, D., Gruber, C., Laimer, M., Thalhamer, J., Hintner, H., Gratz, I. K., and Bauer, J. W. (2012). Transcutaneous gene gun delivery of hNC16A Induces BPAG2-specific tolerance. J. Invest. Dermatol. doi: 10.1038/jid.2012.19. [Epub ahead of print].

Ferguson, T. A., Herndon, J., Elzey, B., Griffith, T. S., Schoenberger, S., and Green, D. R. (2002). Uptake of apoptotic antigen-coupled cells by lymphoid dendritic cells and crosspriming of $\mathrm{CD} 8(+) \mathrm{T}$ cells produce active immune unresponsiveness. $J$. Immunol. 168, 5589-5595.

Finkelman, F. D., Lees, A., Birnbaum, R., Gause, W. C., and Morris, S. C. (1996). Dendritic cells can present antigen in vivo in a tolerogenic or immunogenic fashion. J. Immunol. 157, 1406-1414.

Fong, L., Brockstedt, D., Benike, C. Wu, L., and Engleman, E. G. (2001). Dendritic cells injected via different routes induce immunity in cancer patients. J. Immunol. 166, 4254-4259.

Frick, J. S., Grunebach, F., and Autenrieth, I. B. (2010). Immunomodulation by semi-mature dendritic cells: a novel role of Toll-like receptors and interleukin-6. Int. J. Med. Microbiol. 300, 19-24.

Frick, J. S., Zahir, N., Muller, M., Kahl, F. Bechtold, O., Lutz, M. B., Kirschning, C. J., Reimann, J., Jilge, B., Bohn, E., and Autenrieth, I. B. (2006). Colitogenic and non-colitogenic commensal bacteria differentially trigger DC maturation and Th cell polarization: an important role for IL-6. Eur. J. Immunol. 36, 1537-1547.

Fu, F., Li, Y., Qian, S., Lu, L., Chambers, F., Starzl, T. E., Fung, J. J., and Thomson, A. W. (1996). Costimulatory molecule-deficient dendritic cell progenitors (MHC class II+, CD80dim, CD86-) prolong cardiac allograft survival in nonimmunosuppressed recipients. Transplantation 62, 659-665.

Funk, J. O., Walczak, H., Voigtländer, C., Berchtold, S., Baumeister, T., Rauch, P., Rößner, S., Steinkasserer, A., Schuler, G., and Lutz, M. B. (2000). Cutting edge: resistance to apoptosis and continuous proliferation of dendritic cells deficient for TNF Receptor-1. J. Immunol. 165, 4792-4796.

Ghoreschi, K., Bruck, J., Kellerer, C., Deng, C., Peng, H., Rothfuss, O., Hussain, R. Z., Gocke, A. R., Respa, A., Glocova, I., Valtcheva, N., Alexander, E., Feil, S., Feil, R.,
Schulze-Osthoff, K., Rupec, R. A., Lovett-Racke, A. E., Dringen, R. Racke, M. K., and Rocken, M. (2011). Fumarates improve psoriasis and multiple sclerosis by inducing type II dendritic cells. J. Exp. Med. 208, 2291-2303.

Giannoukakis, N., Phillips, B., Finegold, D., Harnaha, J., and Trucco, M. (2011). Phase I (safety) study of autologous tolerogenic dendritic cells in type 1 diabetic patients. Diabetes Care 34, 2026-2032.

Godfrey, D. I., Macdonald, H. R., Kronenberg, M., Smyth, M. J., and Van Kaer, L. (2004). NKT cells: what's in a name? Nat. Rev. Immunol. 4, 231-237.

Hadeiba, H., Sato, T., Habtezion, A., Oderup, C., Pan, J., and Butcher, E. C. (2008). CCR9 expression defines tolerogenic plasmacytoid dendritic cells able to suppress acute graftversus-host disease. Nat. Immunol. 9 , 1253-1260.

Hänig, J., and Lutz, M. B. (2008). Suppression of mature dendritic cell function by regulatory $\mathrm{T}$ cells in vivo is abrogated by CD40 licensing. $J$. Immunol. 180, 1405-1413.

Hawiger, D., Inaba, K., Dorsett, Y., Guo, M., Mahnke, K., Rivera, M., Ravetch, J. V., Steinman, R. M., and Nussenzweig, M. C. (2001). Dendritic cells induce peripheral $\mathrm{T}$ cell unresponsiveness under steady state conditions in vivo. J. Exp. Med. 194, 769-780.

Hemmi, H., Yoshino, M., Yamazaki, H., Naito, M., Iyoda, T., Omatsu, Y., Shimoyama, S., Letterio, J. J., Nakabayashi, T., Tagaya, H., Yamane, T., Ogawa, M., Nishikawa, S., Ryoke, K., Inaba, K., Hayashi, S., and Kunisada, T. (2001). Skin antigens in the steady state are trafficked to regional lymph nodes by transforming growth factor-beta1dependent cells. Int. Immunol. 13, 695-704.

Henri, S., Guilliams, M., Poulin, L. F., Tamoutounour, S., Ardouin, L., Dalod, M., and Malissen, B. (2010). Disentangling the complexity of the skin dendritic cell network. Immunol. Cell Biol. 88, 366-375.

Henri, S., Vremec, D., Kamath, A., Waithman, J., Williams, S., Benoist, C., Burnham, K., Saeland, S., Handman, E., and Shortman, K. (2001). The dendritic cell populations of mouse lymph nodes. J. Immunol. 167, 741-748

Hilkens, C. M., Isaacs, J. D., and Thomson, A. W. (2010). Development of dendritic cell-based immunotherapy for autoimmunity. Int. Rev Immunol. 29, 156-183. 
Hu, S. X., Sui, H. X., Jin, H. J., Ni, X. Y., Liu, X. X., Xue, M. Q., Zhang, Y., and Gao, F. G. (2012). Lipopolysaccharide and dose of nicotine determine the effects of nicotine on murine bone marrow-derived dendritic cells. Mol. Med. Report. 5, 1005-1010.

Huang, F. P., Platt, N., Wykes, M., Major, J. R., Powell, T. J., Jenkins, C. D., and Macpherson, G. G. (2000). A discrete subpopulation of dendritic cells transports apoptotic intestinal epithelial cells to $\mathrm{T}$ cell areas of mesenteric lymph nodes. J. Exp. Med. 191, 435-444.

Hulse, K. E., and Woodfolk, J. A. (2008). Targeting allergen to $\mathrm{Fc}$ gammaRI: a strategy to treat allergic disease? Curr. Opin. Allergy Clin. Immunol. 8, 547-552.

Jaen, O., Rulle, S., Bessis, N., Zago, A., Boissier, M. C., and Falgarone, G. (2009). Dendritic cells modulated by innate immunity improve collageninduced arthritis and induce regulatory T cells in vivo. Immunology 126, 35-44.

Jiang, A., Bloom, O., Ono, S., Cui, W., Unternaehrer, J., Jiang, S., Whitney, J. A., Connolly, J., Banchereau, J., and Mellman, I. (2007). Disruption of E-cadherin-mediated adhesion induces a functionally distinct pathway of dendritic cell maturation. Immunity 27, 610-624.

Kleindienst, P., Wiethe, C., Lutz, M. B., and Brocker, T. (2005). Simultaneous induction of $\mathrm{CD} 4 \mathrm{~T}$ cell tolerance and CD8 $\mathrm{T}$ cell immunity by semimature dendritic cells. J. Immunol. 174, 3941-3947. [*equal contribution with last author].

Kretschmer, K., Apostolou, I., Hawiger, D., Khazaie, K., Nussenzweig, M. C., and Von Boehmer, H. (2005). Inducing and expanding regulatory $\mathrm{T}$ cell populations by foreign antigen. Nat. Immunol. 6, 1219-1227.

Kuang, D. M., Zhao, Q., Xu, J., Yun, J. P., Wu, C., and Zheng, L. (2008). Tumor-educated tolerogenic dendritic cells induce CD3epsilon down-regulation and apoptosis of $\mathrm{T}$ cells through oxygendependent pathways. J. Immunol. 181, 3089-3098.

Li, H., Zhang, G. X., Chen, Y., Xu, H., Fitzgerald, D. C., Zhao, Z., and Rostami, A. (2008). CD11c+CD11b+ dendritic cells play an important role in intravenous tolerance and the suppression of experimental autoimmune encephalomyelitis. J. Immunol. 181, 2483-2493.

Lim, D. S., Kang, M. S., Jeong, J. A., and Bae, Y. S. (2009). Semimature DC are immunogenic and not tolerogenic when inoculated at a high dose in collagen-induced arthritis mice. Eur. J. Immunol. 39, 1334-1343.

Lutz, M. B., and Schuler, G. (2002). Immature, semi-mature and fully mature dendritic cells: which signals induce tolerance or immunity? Trends Immunol. 23, 445-449.

MacDonald, A. S., and Maizels, R. M. (2008). Alarming dendritic cells for Th2 induction. J. Exp. Med. 205, 13-17.

Maldonado-López, R., De Smedt, T., Michel, P., Godfroid, J., Pajak, B., Heirman, C., Thielemans, K., Leo, O., Urbain, J., and Moser, M. (1999). CD8alphat and CD8alpha- subclasses of dendritic cells direct the development of distinct $\mathrm{T}$ helper cells in vivo. J. Exp. Med. 189, 587-592.

Manicassamy, S., and Pulendran, B. (2011). Dendritic cell control of tolerogenic responses. Immunol. Rev. 241, 206-227.

Manicassamy, S., Reizis, B., Ravindran, R., Nakaya, H., Salazar-Gonzalez, R. M., Wang, Y. C., and Pulendran, B. (2010). Activation of beta-catenin in dendritic cells regulates immunity versus tolerance in the intestine. Science 329, 849-853.

Martin, P., Del Hoyo, G. M., Anjuere, F., Arias, C. F., Vargas, H. H., Fernandez, L. A., Parrillas, V., and Ardavin, C. (2002). Characterization of a new subpopulation of mouse CD8alpha+ B220+ dendritic cells endowed with type 1 interferon production capacity and tolerogenic potential. Blood 100, 383-390.

McGuirk, P., Mccann, C., and Mills, K. H. (2002). Pathogen-specific T regulatory 1 cells induced in the respiratory tract by a bacterial molecule that stimulates interleukin 10 production by dendritic cells: a novel strategy for evasion of protective $\mathrm{T}$ helper type 1 responses by Bordetella pertussis. J. Exp. Med. 195, 221-231.

Menges, M., Rossner, S., Voigtlander, C., Schindler, H., Kukutsch, N. A., Bogdan, C., Erb, K., Schuler, G., and Lutz, M. B. (2002). Repetitive injections of dendritic cells matured with tumor necrosis factor alpha induce antigen-specific protection of mice from autoimmunity. J. Exp. Med. 195, 15-21.

Mills, K. H., and McGuirk, P. (2004). Antigen-specific regulatory $\mathrm{T}$ cells their induction and role in infection. Semin. Immunol. 16, 107-117.

Mondoulet, L., Dioszeghy, V., Larcher, T., Ligouis, M., Dhelft, V., Puteaux, E., Cherel, Y., Letourneur, F., Dupont, C., and Benhamou, P. H.
(2012). Epicutaneous immunotherapy (EPIT) blocks the allergic esophago-gastro-enteropathy induced by sustained oral exposure to peanuts in sensitized mice. PLoS ONE 7, e31967. doi:10.1371/journal.pone.0031967

Mondoulet, L., Dioszeghy, V., Ligouis, M., Dhelft, V., Dupont, C., and Benhamou, P. H. (2010). Epicutaneous immunotherapy on intact skin using a new delivery system in a murine model of allergy. Clin. Exp. Allergy 40, 659-667.

Mondoulet, L., Dioszeghy, V., Vanoirbeek, J. A., Nemery, B., Dupont, C., and Benhamou, P. H. (2011). Epicutaneous immunotherapy using a new epicutaneous delivery system in mice sensitized to peanuts. Int. Arch Allergy Immunol. 154, 299-309.

Moreau, A., Chiffoleau, E., Beriou, G., Deschamps, J. Y., Heslan, M., Ashton-Chess, J., Rolling, F., Josien, R., Moullier, P., Cuturi, M. C., and Alliot-Licht, B. (2008). Superiority of bone marrow-derived dendritic cells over monocyte-derived ones for the expansion of regulatory $\mathrm{T}$ cells in the macaque. Transplantation 85 1351-1356.

Morel, P. A., and Turner, M. S. (2011). Dendritic cells and the maintenance of self-tolerance. Immunol. Res. 50 124-129.

Morelli, A. E., and Larregina, A. T. (2010). Apoptotic cell-based therapies against transplant rejection: role of recipient's dendritic cells. Apoptosis 15, 1083-1097.

Morelli, A. E., Rubin, J. P., Erdos, G., Tkacheva, O. A., Mathers, A. R., Zahorchak, A. F., Thomson, A. W., Falo, L. D. Jr., and Larregina, A. T. (2005). CD4+ T cell responses elicited by different subsets of human skin migratory dendritic cells. J. Immunol. 175 7905-7915.

Morelli, A. E., and Thomson, A. W (2007). Tolerogenic dendritic cells and the quest for transplant tolerance. Nat. Rev. Immunol. 7, 610-621.

Muller, K. P., Schumacher, J., and Kyewski, B. A. (1993). Half-life of antigen/major histocompatibility complex class II complexes in vivo: intra- and interorgan variations. Eur. J. Immunol. 23, 3203-3207.

Nono, J. K., Pletinckx, K., Lutz, M. B., and Brehm, K. (2012). Excretory/secretory-products of Echinococcus multilocularis larvae induce apoptosis and tolerogenic properties in dendritic cells in vitro. PLoS Negl. Trop. Dis. 6, el516.

Nouri-Shirazi, M., and Thomson, A. W. (2006). Dendritic cells as promoters of transplant tolerance. Expert Opin. Biol. Ther. 6, 325-339.

Ochando, J. C., Homma, C., Yang, Y., Hidalgo, A., Garin, A., Tacke, F., Angeli, V., Li, Y., Boros, P., Ding, Y., Jessberger, R., Trinchieri, G., Lira, S. A., Randolph, G. J., and Bromberg, J. S. (2006). Alloantigen-presenting plasmacytoid dendritic cells mediate tolerance to vascularized grafts. Nat. Immunol. 7, 652-662.

O'Garra, A., Vieira, P. L., Vieira, P., and Goldfeld, A. E. (2004). IL-10producing and naturally occurring CD4+ Tregs: limiting collateral damage. J. Clin. Invest. 114, 1372-1378.

Ohl, L., Mohaupt, M., Czeloth, N., Hintzen, G., Kiafard, Z., Zwirner, J., Blankenstein, T., Henning, G., and Forster, R. (2004). CCR7 governs skin dendritic cell migration under inflammatory and steady-state conditions. Immunity 21, 279-288.

Ohnmacht, C., Pullner, A., King, S. B. Drexler, I., Meier, S., Brocker, T., and Voehringer, D. (2009). Constitutive ablation of dendritic cells breaks self-tolerance of CD4 $\mathrm{T}$ cells and results in spontaneous fatal autoimmunity. J. Exp. Med. 206, 549-559.

Perrot, I., Blanchard, D., Freymond, N., Isaac, S., Guibert, B., Pacheco, Y., and Lebecque, S. (2007). Dendritic cells infiltrating human non-small cell lung cancer are blocked at immature stage. J. Immunol. 178, 2763-2769.

Pletinckx, K., Döhler, A., Pavlovic, V., and Lutz, M. B. (2011a). Role of dendritic cell maturity/costimulation for generation, homeostasis and suppressive activity of regulatory $\mathrm{T}$ cells. Front. Immunol. 2:39. doi:10.3389/fimmu.2011.00039

Pletinckx, K., Stijlemans, B., Pavlovic, V., Laube, R., Brandl, C., Kneitz, S., Beschin, A., De Baetselier, P., and Lutz, M. B. (2011b). Similar inflammatory DC maturation signatures induced by TNF or Trypanosoma brucei antigens instruct default Th2cell responses. Eur. J. Immunol. 41, 3479-3494.

Prina, E., Abdi, S. Z., Lebastard, M., Perret, E., Winter, N., and Antoine, J. C. (2004). Dendritic cells as host cells for the promastigote and amastigote stages of Leishmania amazonensis: the role of opsonins in parasite uptake and dendritic cell maturation. J. Cell Sci. 117, 315-325.

Remer, K. A., Apetrei, C., Schwarz, T., Linden, C., and Moll, $\mathrm{H}$ (2007). Vaccination with plasmacytoid dendritic cells induces protection against infection with Leishmania major in mice. Eur. J. Immunol 37, 2463-2473. 
Romani, N., Clausen, B. E., and Stoitzner, P. (2010). Langerhans cells and more: langerin-expressing dendritic cell subsets in the skin. Immunol. Rev. 234, 120-141.

Roncarolo, M. G., Gregori, S., Battaglia, M., Bacchetta, R., Fleischhauer, K., and Levings, M. K. (2006). Interleukin-10-secreting type 1 regulatory $\mathrm{T}$ cells in rodents and humans. Immunol. Rev. 212, 28-50.

Ruedl, C., Koebel, P., Bachmann, M., Hess, M., and Karjalainen, K. (2000). Anatomical origin of dendritic cells determines their life span in peripheral lymph nodes. J. Immunol. 165, 4910-4916.

Ruedl, C., Koebel, P., and Karjalainen, K. (2001). In vivo-matured Langerhans cells continue to take up and process native proteins unlike in vitromatured counterparts. J. Immunol. 166, 7178-7182.

Rutella, S., Danese, S., and Leone, G. (2006). Tolerogenic dendritic cells: cytokine modulation comes of age. Blood 108, 1435-1440.

Sato, K., Yamashita, N., Baba, M., and Matsuyama, T. (2003a). Modified myeloid dendritic cells act as regulatory dendritic cells to induce anergic and regulatory $\mathrm{T}$ cells. Blood 101, 3581-3589.

Sato, K., Yamashita, N., Baba, M., and Matsuyama, T. (2003b). Regulatory dendritic cells protect mice from murine acute graft-versus-host disease and leukemia relapse. Immunity 18, 367-379.

Senti, G., Freiburghaus, A. U., and Kundig, T. M. (2010). Epicutaneous/transcutaneous allergen-specific immunotherapy: rationale and clinical trials. Curr. Opin. Allergy Clin. Immunol. 10, 582-586.

Senti, G., Graf, N., Haug, S., Ruedi, N., Von Moos, S., Sonderegger, T., Johansen, P., and Kundig, T. M. (2009). Epicutaneous allergen administration as a novel method of allergen-specific immunotherapy. J. Allergy Clin. Immunol. 124, 997-1002.

Senti, G., Von Moos, S., and Kundig, T. M. (2011). Epicutaneous allergen administration: is this the future of allergen-specific immunotherapy? Allergy 66, 798-809.

Smed-Sorensen, A., and Lore, K. (2011). Dendritic cells at the interface of innate and adaptive immunity to HIV-1. Curr. Opin. HIV AIDS 6, 405-410.

Steinman, R. M. (2008). Dendritic cells in vivo: a key target for a new vaccine science. Immunity 29, 319-324.

Steinman, R. M., Turley, S., Mellman, I., and Inaba, K. (2000). The induction of tolerance by dendritic cells that have captured apoptotic cells. J. Exp. Med. 191, 411-416.

Stoop, J. N., Harry, R. A., Von Delwig, A., Isaacs, J. D., Robinson, J. H., and Hilkens, C. M. (2010). Therapeutic effect of tolerogenic dendritic cells in established collagen-induced arthritis is associated with a reduction in Th17 responses. Arthritis Rheum. 62, 3656-3665.

Summers, K. L., Hock, B. D., Mckenzie, J. L., and Hart, D. N. (2001). Phenotypic characterization of five dendritic cell subsets in human tonsils. Am. J. Pathol. 159, 285-295.

Szczepanik, M., Tutaj, M., Bryniarski, K., and Dittel, B. N. (2005). Epicutaneously induced TGF-beta-dependent tolerance inhibits experimental autoimmune encephalomyelitis. J. Neuroimmunol. 164, 105-114.

Thomson, A. W. (2010). Tolerogenic dendritic cells: all present and correct? Am. J. Transplant. 10, 214-219.

Tjomsland, V., Spangeus, A., Sandstrom, P., Borch, K., Messmer, D., and Larsson, M. (2010). Semi mature blood dendritic cells exist in patients with ductal pancreatic adenocarcinoma owing to inflammatory factors released from the tumor. PLoS ONE 5, e13441. doi:10.1371/journal.pone.0013441

Unger, W. W., Laban, S., Kleijwegt, F. S., Van Der Slik, A. R., and Roep, B. O. (2009). Induction of Treg by monocyte-derived DC modulated by vitamin D3 or dexamethasone: differential role for PD-L1. Eur. J. Immunol. 39, 3147-3159.

van de Ven, R., Van Den Hout, M. F., Lindenberg, J. J., Sluijter, B. J., Van Leeuwen, P. A., Lougheed, S. M., Meijer, S., Van Den Tol, M. P., Scheper, R. J., and De Gruijl, T. D. (2011). Characterization of four conventional dendritic cell subsets in human skin-draining lymph nodes in relation to T-cell activation. Blood 118, 2502-2510.

van Duivenvoorde, L. M., Van Mierlo, G. J., Boonman, Z. F., and Toes, R. E. (2006). Dendritic cells: vehicles for tolerance induction and prevention of autoimmune diseases. Immunobiology 211, 627-632.

Veckman, V., Miettinen, M., Pirhonen, J., Siren, J., Matikainen, S., and Julkunen, I. (2004). Streptococcus pyogenes and Lactobacillus rhamnosus differentially induce maturation and production of Th1-type cytokines and chemokines in human monocyte-derived dendritic cells. J. Leukoc. Biol. 75, 764-771.

Verginis, P., Li, H. S., and Carayanniotis, G. (2005). Tolerogenic semimature dendritic cells suppress experimental autoimmune thyroiditis by activation of thyroglobulin-specific CD4+CD25+ T cells. J. Immunol. 174, 7433-7439.

Voigtländer, C., Rößner, S., Cierpka, E. Theiner, G., Wiethe, C., Menges, M. Schuler, G., and Lutz, M. B. (2006). Dendritic cells matured with TNF can be further activated in vitro and after subcutaneous injection in vivo which converts their tolerogenicity into immunogenicity. $J$. Immunother. 29, 407-415.

Vojtova, J., Kamanova, J., and Sebo, P. (2006). Bordetella adenylate cyclase toxin: a swift saboteur of host defense. Curr. Opin. Microbiol. 9, 69-75.

Waithman, J., Allan, R. S., Kosaka, H., Azukizawa, H., Shortman, K., Lutz, M. B., Heath, W. R., Carbone, F. R., and Belz, G. T. (2007). Skin-derived dendritic cells can mediate deletional tolerance of class I-restricted self-reactive T cells. J. Immunol. 179, 4535-4541.

Wendland, M., Willenzon, S., Kocks, J. Davalos-Misslitz, A. C., Hammerschmidt, S. I., Schumann, K., Kremmer, E., Sixt, M., Hoffmeyer, A., Pabst, O., and Forster, R. (2011). Lymph node $\mathrm{T}$ cell homeostasis relies on steady state homing of dendritic cells. Immunity 35, 945-957.

Werfel, T. (2009). Epicutaneous allergen administration: a novel approach for allergen-specific immunotherapy? J. Allergy Clin. Immunol. 124, 1003-1004.

Wiethe, C., Debus, A., Mohrs, M. Steinkasserer, A., Lutz, M. B. and Gessner, A. (2008). Dendritic cell differentiation state and their interaction with NKT cells determine Th1/Th2 differentiation in the murine model of Leishmania major infection. J. Immunol. 180, 4371-4381.

Wiethe, C., Schiemann, M., Busch, D. Haeberle, L., Kopf, M., Schuler, G. and Lutz, M. B. (2007). Interdependency of MHC class II/self-peptide and CD1d/self-glycolipid presentation by TNF-matured dendritic cells for protection from autoimmunity. J. Immunol. 178, 4908-4916.

Wilson, N. S., El-Sukkari, D., Belz, G. T., Smith, C. M., Steptoe, R. J., Heath,
W. R., Shortman, K., and Villadangos, J. A. (2003). Most lymphoid organ dendritic cell types are phenotypically and functionally immature. Blood 102, 2187-2194.

Worbs, T., Bode, U., Yan, S., Hoffmann, M. W., Hintzen, G., Bernhardt, G., Forster, R., and Pabst, O. (2006). Oral tolerance originates in the intestinal immune system and relies on antigen carriage by dendritic cells. J. Exp. Med. 203, 519-527.

Yamazaki, S., Dudziak, D., Heidkamp, G. F., Fiorese, C., Bonito, A. J. Inaba, K., Nussenzweig, M. C., and Steinman, R. M. (2008). CD8+ CD205+ splenic dendritic cells are specialized to induce Foxp3+ regulatory $\mathrm{T}$ cells. J. Immunol. 181, 6923-6933.

Yang, X. J., Meng, S., Zhu, C. F., Jiang, H., and Wu, W. X. (2011). Semi-mature MyD88-silenced bone marrow dendritic cells prolong the allograft survival in a rat model of intestinal transplantation. Chin. Med. J. 124, 268-272.

Young, J. W., Merad, M., and Hart, D. N. (2007). Dendritic cells in transplantation and immune-based therapies. Biol. Blood Marrow Transplant. 13, 23-32.

Zozulya, A. L., Ortler, S., Lee, J., Weidenfeller, C., Sandor, M., Wiendl, H., and Fabry, Z. (2009). Intracerebral dendritic cells critically modulate encephalitogenic versus regulatory immune responses in the CNS. J. Neurosci. 29, 140-152.

Conflict of Interest Statement: The author declares that the research was conducted in the absence of any commercial or financial relationships that could be construed as a potential conflict of interest.

Received: 20 March 2012; accepted: 30 April 2012; published online: 18 May 2012.

Citation: Lutz MB (2012) Therapeutic potential of semi-mature dendritic cells for tolerance induction. Front. Immun. 3:123. doi: 10.3389/fimmu.2012.00123 This article was submitted to Frontiers in Immunological Tolerance, a specialty of Frontiers in Immunology.

Copyright () 2012 Lutz. This is an openaccess article distributed under the terms of the Creative Commons Attribution Non Commercial License, which permits non-commercial use, distribution, and reproduction in other forums, provided the original authors and source are credited. 